\title{
MANEJO DE LAS HERIDAS QUIRÚRGICAS, DESDE EL TIPO, TÉCNICA E INSUMOS UTILIZADOS EN UNA IPS”. ARMENIA, QUINDÍO, 2014
}

\author{
MANAGEMENT OF SURGICAL WOUNDS CONSIDERING THE TYPE, TECHNIQUE AND \\ SUPPLIES USED IN AN A HEALTH PROVIDING INSTITUTION." ARMENIA, QUINDÍO, 2014
}

Adiela Henao Buriticá*1, Carmen Aydé Fernández Rincón ${ }^{1}$, Nancy García García y Paola Orozco Gómez²

${ }^{1 .}$ Facultad de Ciencias de la salud, Programas de Enfermería, Grupo de Investigación GRIEQ.

2. Hospital Universitario San Juan De Dios Armenia-Quindío

Recibido: 10 de Septiembre de 2014

Aceptado: 30 de Noviembre de 2014

*Correspondencia del autor. Facultad de Ciencias de la Salud, Programa de Enfermería.

E-mail: aheanob@uniquindio.edu.co

\section{RESUMEN:}

Este artículo surge de la investigación "Manejo de las heridas quirúrgicas, desde el tipo, técnica e insumos utilizados en una ips. Armenia, Quindio, 2014, financiado por la Vicerrectoría de Investigaciones de la Universidad del Quindío. La investigación describe los métodos que son manejados para el cuidado de las heridas por parte del personal de enfermería que realiza dicho procedimiento, con el fin de conocer con detalle la técnica, o técnicas, y los procesos utilizados en el procedimiento, materiales, pasos, asepsia, entre otros; contrasta lo observado con los avances científicos-tecnológicos en este campo y determina el cuidado de enfermería brindado a los pacientes adultos hospitalizados con heridas de diferente etiología. La investigación fue de tipo Descriptiva-Transversal, con enfoque cuantitativo. La muestra se obtuvo a través de un muestreo intencional, para este caso, pacientes con herida quirúrgica hospitalizados en los servicios quirúrgicos, que ingresaron durante un trimestre por cirugía programada, complicaciones quirúrgicas o por cirugía de urgencia, en una IPS de tercer nivel de atención de Armenia, y quienes eligieron voluntariamente su participación. La técnica para la recolección de la información fue a través de la filmación del procedimiento. Posteriormente, se diligenciaron los instrumentos diseñados para los fines de la investigación; los datos fueron ingresados a Bases de Datos construidas y procesadas en SPSS.

Palabras claves: Cuidado, Curación, Enfermería, Heridas, Ser Humano. 


\begin{abstract}
This article is about the procedures and results of the research "Manejo de las heridas quirúrgicas, desde el tipo, técnica e insumos utilizados en una ips. Armenia, Quindío, 2014. Its main purpose was to describe the methods managed by nursing staff for wound care in the procedures, in order to know in detail the techniques and processes used in the procedure (materials, steps, sepsis, etc.), contrasting these with scientific and technological advances in this field and at last determine nursing care provided to hospitalized adult patients with wounds of different etiology. The research was transversal descriptive and the sample was obtained through purposive sampling; surgical wound of hospitalized patients in surgical departments, admitted during a trimester by elective surgery, surgical complications or emergency surgery, in a third level hospital of care. The people studied had the opportunity to voluntarily choose their participation. The technique for data collection was video recording the proceedings; subsequently the guide for supplementary information was filled, the data was carried out to a Databases built and processed in SPSS. Results: 51 patients were analyzed: 29 from general surgery, 3 from neurosurgery, 11 from orthopedics, 2 from plastic surgery , 4 from internal medicine, and 2 from urology. Findings: The handling of the wound continues being traditional with products provided by the institution such as gauze, dressings, saline, Furacin and alcohol. However, there are products that contribute to effective healing care of the wound or debridement. These are seldom used, and the use of polyvinyl in open wounds was evident.

The techniques were found inadequate; the procedure is not done in a systematic way (auxiliary or professional staff). There documentation process is not efficient, privacy aspects and comfort (secondary) are not taken into account, the educational approach patient / family is irrelevant. Recommendations: Resume leadership from the professional nurses, management in care of the person injured. This would result in the identification and institutional availability of equipment, supplies and care items. Resume the rigorous biosecurity update protocols and ensure staff adherence to wound care according to scientific advance, sensitize all health team around humanized care, develop processes in institutional tracking and monitoring to ensure infection control; and structure processes of induction and re-induction to staff.
\end{abstract}

Keywords: Care, Healing, Nursing, Wounds, Human Beings.

\section{INTRODUCCIÓN}

En la edad media se contaba con múltiples investigadores, hecho reflejado en celebres frases del devenir en la evolución de las heridas quirúrgicas como: "Lo esperado no sucede, es lo inesperado lo que acontece." (Ernesto Sábato) Estas primeras experiencias registradas trazan las rutas a los investigadores que fueron pioneros en el amplio camino que debían seguir, para obtener un resultado óptimo a todos sus esfuerzos.

La historia de la cirugía está íntimamente ligada a la evolución de las personas que "cuidaban la salud" y, en ese contexto, las heridas. No siempre existía un hilo de sutura para cada herida, sino que, de acuerdo con las costumbres de su población, utilizaban diferentes técnicas, materiales y destrezas acordes con su conocimiento empírico.
Durante la segunda guerra mundial se emplearon cataplasmas hechos con la savia de nopal y otras plantas mezcladas con miel y yema de huevo, que le daban la consistencia adhesiva necesaria para proteger el proceso natural de curación. Las heridas por arma de fuego se consideraban envenenadas por la pólvora y para su cura se cauterizaba con aceite de sauco caliente hasta escaldar, que se aplicaba dentro de la herida, lo cual causaba dolor al paciente, fiebre y tumefacción en torno de las heridas; por lo que se optó por usar una mezcla de yema de huevo, aceite de rosas y terebinto que producía menos dolor y no generaba inflamación, ni tumefacción.

Como se aprecia, existe un largo y fructífero proceso histórico en torno al cuidado de las heridas. Aún en nuestro tiempo se sigue investigando sobre diversos métodos para el manejo de heridas, algunos más costosos que otros, pero con la misma finalidad: disminuir las complicaciones y el tiempo de cicatrización. 
A nivel nacional y departamental, por varias décadas se han utilizado diferentes materiales para el manejo de las heridas quirúrgicas como la hoja de papaya, azúcar pulverizada y panela. En este mismo sentido, se han utilizado los bactericidas tópicos, la solución salina normal (SSN) y material como gasas y apósitos para la limpieza de las heridas. En algunas ocasiones se utilizan los apósitos oclusivos húmedos a base de celulosa y otros materiales con tecnología de punta que favorecen la cicatrización en medio húmedo, con excelentes resultados. Además, los trámites administrativos de los formatos no POSS son muy dispendiosos porque no lo realizan a tiempo, con la desventaja de los altos costos (1). Sin embargo, su utilización ha sido específicamente en algunos pacientes porque el insumo lo debe comprar la red de apoyo, y no existe además unificación de criterios en el personal que realiza este manejo.

En el Quindío, los cirujanos comenzaron a emplear el polivinilo como prótesis peritoneal en abdomen abierto al observar que la fricción continúa y la desecación tisular en pacientes con prótesis de polipropileno producían adherencias de las asas intestinales que llegaron a ocasionar fístulas enterocutáneas, las cuales incrementaron los costos al paciente, su familia y la institución, representados en curaciones, materiales y reintervenciones que a la vez ocasionan incremento de la morbimortalidad. El uso del polivinilo dio excelentes resultados como método alternativo para el manejo de abdomen abierto con lavado peritoneal, (1) lo demostraron en el estudio que permitió valorar el efecto del polivinilo en el manejo de heridas abiertas usándolo como método alternativo, con el fin de favorecer el proceso de cicatrización en medio húmedo, en un hospital de atención de tercer nivel de Armenia, Quindío. Los dos tratamientos, gasa-tradicional- y medio húmedo con polivinilo, mostraron eficacia y efectividad con respecto a la curación, siendo relevante el uso del polivinilo como medio húmedo en el manejo de las heridas con pérdida de tejido, en cual se disminuyó costos en el paciente y en la institución.

Adicional a lo anterior, se encuentra la existencia de protocolos del cuidado de la herida, asunto en el cual no se han realizado investigaciones pertinentes que avalen el nivel de cumplimiento y su consecuente la efectividad. Más del 50\% de los pacientes hospitalizados en los servicios de cirugía presentan heridas de diversas etiologías como politraumatismos, lesiones por arma de fuego y corto punzantes, y patologías quirúrgicas.

Los aspectos anteriormente presentados sustentan la realizacion de esta investigación cuyo propósito fundamental fue el de responder a la pregunta ¿ Cuál es el manejo de las heridas quirúrgicas, desde el tipo, técnica e insumos utilizados en una IPS ?

\section{REFERENTES TEÓRICOS Piel Y Cicatrización}

La piel está formada por dos capas principales: la epidermis, capa externa delgada, y la dermis, capa interna más gruesa. La epidermis no es vascular y está compuesta principalmente por células epiteliales, cuenta con cinco capas en las palmas de las manos y las plantas de los pies; en el resto del cuerpo sólo con cuatro. La epidermis se renueva cada 7 a 9 días; su capa externa, llamada córnea, se descama en forma continua, esta capa en los ancianos es particularmente gruesa. La piel ejerce diversas funciones: protege al organismo contra bacterias y otros peligros ambientales, ayuda a la termorregulación, a la producción de vitaminas, a la excreción de productos de desecho y actúa como trasmisor sensor. Debajo de la capa subcutánea se encuentran la aponeurosis, los músculos y los huesos. Estos tejidos se encuentran bien vascularizados.

A medida que la piel envejece la capa epitelial y la capa grasa se adelgazan, el colágeno y las fibras elásticas se encogen y las glándulas sudoríparas disminuyen. La piel se adelgaza, se seca y no es elástica, su integridad puede ser rota con facilidad, lo que hace a la persona más susceptible a la infección. (Harper, 1972).

El proceso de cicatrización comienza inmediatamente después de la lesión. Cuando los tejidos se rompen, los vasos sufren, las células se dañan y las plaquetas y el colágeno reaccionan rápidamente; desde ese momento, inicia la regeneración de células y la reparación de tejidos.

La cicatrización es un proceso biológico y complejo, con fases catabólicas y anabólicas en las que participan procesos bioquímicos y celulares. Fase exudativa o inflamatoria: Se inicia desde el momento en que ocurre la lesión y dura aproximadamente de 3 a 4 días contados a partir de su ocurrencia, suceden procesos de homeostasis y fagocitosis. Por activación del sistema de coagulación, específicamente el factor XIII, 
estabilizador de la fibrina, quien forma monómeros entrelazados que facilitan la migración de los fibroblastos, los cuales van a producir colágeno. La dilatación de los vasos cercanos trae como resultado un derrame vascular y en consecuencia edema del tejido, contiene proteínas de suero, enzimas, anticuerpos y una serie de factores de crecimiento liberados por las plaquetas que son esenciales para la cicatrización. Los neutrófilos, o leucocitos polimorfo-nucleares, son defensas tempranas contra la invasión de microbios. Enseguida, los macrófagos asimilan los microbios y tejido muerto y liberan químicos vasodilatadores, ocasionando el enrojecimiento, eritema, y la hinchazón, edema, que son los signos clínicos de la inflamación. Los macrófagos o monocitos, reemplazan los polimorfo-nucleares. A medida que aumentan los macrófagos, estimulan la formación de fibroblastos, quienes a su vez, estimulan la producción de colágeno, principal componente del tejido conectivo. Clínicamente, en la fase inflamatoria una herida se ve enrojecida e hinchada. La inflamación es esencial para el proceso normal de cicatrización, pero debe terminar antes de que progrese la cicatrización. Fase Proliferativa: Esta fase dura aproximadamente de 4 a 24 días, los fibroblastos proliferan y a medida que estos se multiplican la cantidad de colágeno que se deposita aumenta y se forman nuevos vasos sanguíneos en toda la herida; aquí se produce la revascularización y el tejido de granulación, los nuevos vasos proveen de nutrición a los tejidos que se están regenerando, el epitelio comienza a emigrar a través de la herida para rellenar el defecto. El tejido brillante, rojo y carnoso que sangra fácilmente es el tejido de granulación. Este tejido rellena la herida y brinda una superficie para la epitelización. Las células epiteliales se dividen y migran de los bordes de la herida. El tejido epitelial es rosado y puede estar presente en pequeñas áreas a través de toda la herida. La contracción es el proceso mediante el cual los bordes de la herida se mueven hacia el centro, disminuyendo el tamaño del lecho de la herida. Fase de maduración: La fase de maduración o remodelación, es la más larga; empieza alrededor del día 24 después de ocurrida la lesión y puede durar un año o más. Durante este tiempo las fibras de colágeno se reorganizan y remodelan. Las células envejecen, volviéndose menos vascularizadas y ganando resistencia tensora. La cicatriz puede eventualmente recuperar hasta un $80 \%$ de su resistencia original, pero siempre será inferior en su estructura al tejido inicial.

\section{REFERENTE DE MODELOS Y TEORÍAS DE ENFERMERIA.}

Como filosofía de la enfermería resaltamos el trabajo de Watson (3), con el cual nos identificamos plenamente: Se evidencia una visión fenomenológica-existencialista y humanística del cuidado de los enfermos como un fenómeno social universal que solo resulta efectivo si se practica de forma interpersonal; dice que la enfermería se dedica a la promoción y restablecimiento de la salud y la prevención de la enfermedad; los pacientes requieren unos cuidados holísticos que promuevan el humanismo, la salud y la calidad de vida.

Watson (3), reconoce que el cuidar es parte fundamental del ser, es la base fundadora del cuidado en general y, a la vez, del cuidado profesional propio de la enfermería; el cuidado profesional es estructurado, formalizado y destinado a satisfacer las necesidades del ser humano con el propósito de promover, mantener o recuperar la salud. El cuidado sanitario tiene metas específicas, se apoya en un contexto epistemológico, y se formaliza y desarrolla por medio de una serie de técnicas aprendidas en la formación profesional de enfermería, lo que implica una transformación de nuestro ser y nuestras prácticas.

"El cuidado humanizado, debe considerar un entramado en primer momento de la presencia del personal tanto física, mental y espiritual, que brinde seguridad al paciente y que su cuidado sea holístico, considerando los procesos a los cuales se somete al paciente" (3).

El Modelo de Peplau, se centra en la Teoría de relaciones interpersonales y destaca la importancia de la enfermera/o en el proceso interpersonal definido como terapeútico. La personalidad de la enfermera/o es muy importante tanto, por la influencia que pueda provocar en sí misma como para el paciente. Rol de suministradora de recursos: la enfermera debe ofrecer respuestas específicas, explicando alpaciente el plan de tratamiento a seguir, teniendo en cuenta la situación eligiendo la respuesta más adecuada dirigida a un aprendizaje constructivo. Rol de educadora: Es una combinación de todos los roles y debe valerce de lo que sabe el paciente, y en función de su interés y capacidad para usar la información. Peplau (4), afirma que el cuidado de enfermería es un proceso significativo, terapéutico e interpersonal, funciona en cooperación con otros procesos humanos los cuales 
hacen que la salud sea posible para los individuos.

\section{OBJETIVO GENERAL.}

Caracterizar el manejo de las heridas quirúrgicas, desde el tipo, técnica einsumos utilizados en una IPS de la ciudad deArmenia(Q) 2013 y el primer semestre del 2014.

\section{OBJETIVOS ESPECÍFICOS.}

- Identificar el tipo de herida quirúrgica según su localización, causas, especialidad médica y tipo de herida: abierta y cerradas, simples y complicadas.

- Reconocer el procedimiento desarrollado en el manejo de las heridas quirúrgicas.

- Identificar los materiales e insumos utilizados en cada uno de los métodos para el cuidado de la herida quirúrgica de los pacientes.

- Analizar los diferentes rituales utilizadas en el momento de realizar el cuidado de las heridas.

\section{MATERIALES Y MÉTODOS.}

Enfoque cuantitativo, tipo descriptivo, transversal. La investigación se realizó en el contexto de un hospital de tercer nivel de atención, relacionada con la caracterización en el manejo de la herida quirúrgica de diferentes etiologías, en los servicios quirúrgicos, con descripción en detalle del proceso desde el tipo, técnica e insumos utilizados durante su cuidado. Inicialmente se realizó una filmación al procedimiento del cuidado de la herida, según orientación de bioética, previo consentimiento del paciente, de los acompañantes y del personal. Posteriormente, se realizó el registro de cada uno de los pasos, materiales e insumos utilizados, entre otros, en los formatos diseñados para tal fin. Se efectuó el registro teniendo como guía una matriz de observación estructurada para definir el proceso, la cual se le aplicó al personal que en el momento estaba realizando la curación. Se tomó, además de la historia clínica, los datos para registrar en uno de los instrumentos la información sobre localización y etiología de la herida quirúrgica. La información fue registrada en un total de nueve instrumentos que permitieron identificar: tipos de heridas, localización por anatomía de superficie de la herida quirúrgica de acuerdo con su tipología y especialidad, la técnica, las características de la heridas, los insumos para cuidar la herida, la adherencia al protocolo institucional, reconocimiento de factores presentes que influyen en el proceso de cicatrización, consentimiento informado.

Sumado a lo anterior, se diseñó una ruta bioética con el propósito de informar acerca de eventos adversos, recomendado por bioética para establecer por parte de la institución planes de mejoramiento. La información obtenida a través de los diferentes instrumentos posteriormente fue llevada a las bases de datos realizados en SSPS, para su sistematización, análisis e interpretación desde la teoría, generando así los resultados, conceptualización y recomendaciones; en el proceso de análisis de resultados desde el enfoque cuantitativo de tipo descriptivo el proceso en esta investigación está enmarcado en tres fases de tratamiento para el análisis de las variables de los datos que consiste en: medir, describir y valorar, permitiéndonos desde la estadística descriptiva permitiendo evidenciar todo el proceso y poder lograr dar respuesta a nuestra pregunta de investigación. Población: Pacientes mayores de 15 años, hospitalizados en los servicios quirúrgicos de una IPS de la ciudad de Armenia Quindío. Muestra Y Tipo De Muestreo. Se realiza presentación ante el comité de bioética e investigación en la IPS de III nivel del proyecto de investigación obteniendo concepto de viabilidad y aprobación para su ejecución, posterior a ello se socializo en los servicios al recurso humano del proceso de investigación, se procedió a tomar un muestreo intencional de 51 pacientes que ingresaron con herida quirúrgica a los servicios de Quirúrgicas de una IPS de la ciudad de Armenia ,Quindio teniendo en cuenta la participación voluntaria y el consentimiento informado tanto del usuario, cuidador, responsable del paciente, enfermera, auxiliar de enfermería, escuelas y universidades en convenios docencia servicio con la IPS.

Técnica De Recolección De Los Datos: para la obtención de la información se realizaron las filmaciones (enfermeros diferentes a las investigadoras), los consentimientos informados respectivos se diligenciaron el día anterior a las filmaciones, teniendo en cuenta al paciente y su red de apoyo para su autorización. Se utilizaron 7 (Siete) instrumentos tales como: Consentimiento informado tipos de heridas, localización por anatomía de superficie de la herida quirúrgica de acuerdo a su tipología y especialidad, según la técnica, características de las heridas, insumos para evaluar la herida, protocolo institucional de las heridas, factores que influyen en el proceso de cicatrización.

Variables Del Estudio: Se desarrolló mediante un proceso descriptivo el cual tuvo variables que se operacionalizaron para lograr la objetividad máxima del estudio, algunas de ellas son: técnica, frecuencia, ri- 
tual, material, herida, curación de la herida, clasificación de la herida quirúrgica, quien realizó la curación de la herida, entre otras

Prueba Piloto: una vez operacionalizadas las variables previa a la recolección definitiva de la información, se realizó una prueba piloto con 5 (cinco) pacientes que permitió poner a prueba, la confiabilidad y validez de los instrumentos, mediante el método de formas alternativas paralelas (5), logrando realizar un filtro objetivo para las variables que se consideraron útiles para el estudio de tal manera que su depuración y diseño proporcionó una confiabilidad y validez del $100 \%$ con el fin de detectar las dificultades operativas y poder realizar los ajustes pertinentes, en donde se modificaron algunos aspectos que optimizaron la aplicación de los instrumentos.

\section{Trabajo De Campo - Recolección De Información}

La recolección de los datos corresponde directamente con el logro de los objetivos planteados en el proyecto de investigación y a las particularidades de la realidad del contexto de los participantes. Se realizaron filmaciones de los procedimientos de la curación de los pacientes con heridas, aplicación de los instrumentos y descripción de las heridas y las observaciones estructuradas.

\section{RESULTADOS Y DISCUSIÓN \\ Las heridas desde las dimensiones descrip- tivas según operacionalizacion de variables "intrumentos"(tipo descriptivo: localizacion, espe- cialidad, complejidad y causas).}

A continuación se presentan los resultados en cuanto a las características del paciente como son edad, sexo, la ubicación del servicio, vinculación al Sistema general de seguridad social en salud (SGSSS); se realiza una descripción de las heridas en cuanto a su tipología, localización anatómica y la especialidad, con el fin de determinar las condiciones externas e internas presentes en los procesos de cicatrización que influyeron en la recuperación de los pacientes incluidos en esta investigación.
La muestra total fue de 51 pacientes, con edades que oscilaban entre los 15 y 84 años, con un media de 45.4 años; de los cuales, el $64.7 \%$ correspondió a hombres y $35.3 \%$, a mujeres, ubicados en los servicios de quirúrgica hombres y quirúrgica mujeres respectivamente. Su vinculación al sistema general de seguridad social fue de $29.4 \%$, vinculados; $47 \%$, subsidiados, $13.7 \%$, SOAT y contributivos $9.8 \%$.

La capacidad de regeneración de la piel decrece con la edad siendo este uno de los factores intrínsecos a tener en cuenta. Con los años, la piel contiene menos colágeno por lo que es menos elástica, soporta peor las fuerzas mecánicas y el tejido es por ende más frágil (6)

En lo referente al tipo de la herida, se encontró que el $68.6 \%$ era aguda y el $31.4 \%$, crónica. Con relación a la clase de heridas, un $29.4 \%$ era abierta; $49 \%$, cerradas y $17.7 \%$, complicadas; un $3.9 \%$, con injerto y fístula entero cutánea.

Ante la presencia de una herida aguda deben valorarse las repercusiones sobre el paciente y su estilo de vida, incluyendo su estado general. Con las heridas crónicas debe prevalecer el enfoque etiológico antes de iniciar cualquier forma de tratamiento. Es trascendental que se generen modelos de tratamiento de aceptación internacional para poder comparar las nuevas modalidades terapéuticas en términos de eficacia, prevención de infecciones y efectos sobre la calidad de vida. (7)

En cuanto a la clasificación de los tipos de heridas, se encontró que el $2.0 \%$ eran punzantes; $3.9 \%$, cortantes; $5.9 \%$, punzocortantes; $17.6 \%$, contusa; $5.9 \%$, heridas por presión; $2.0 \%$, arma de fuego; distribuidas de la siguiente manera, según su ubicación: 2.0\% de heridas de cara y cuello, 49\%, heridas abdominales; 3.9\%, heridas en MMII (vasculares); 3.9\%, heridas en miembros superiores e inferiores (fracturas); $2.0 \%$, latero posterior (lumbar) y $2.0 \%$, inmunológicas (Soaps). (Ver Grafica 1) 


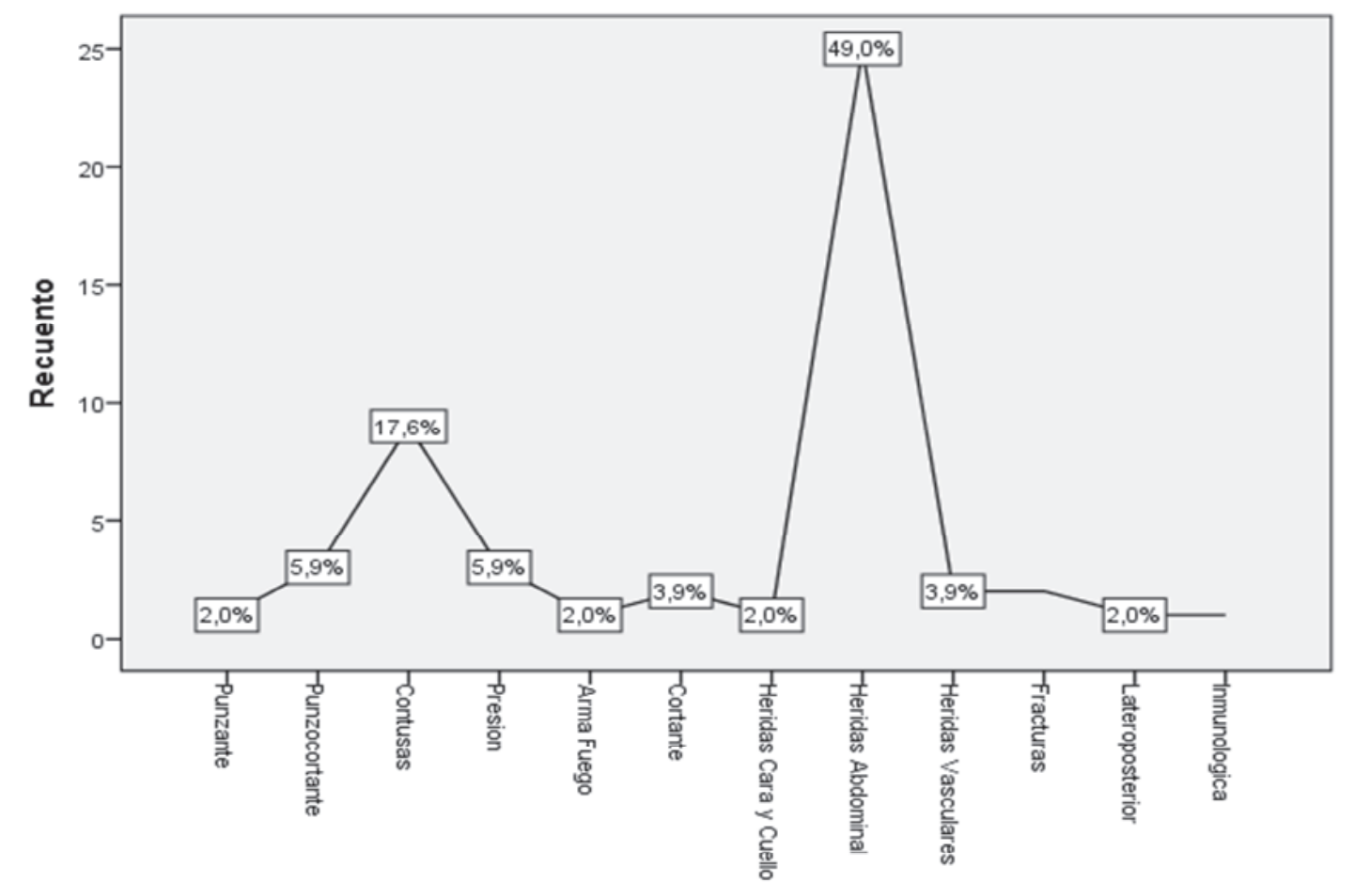

Tipo de Herida

Gráfica 1: clasificación tipo de herida.

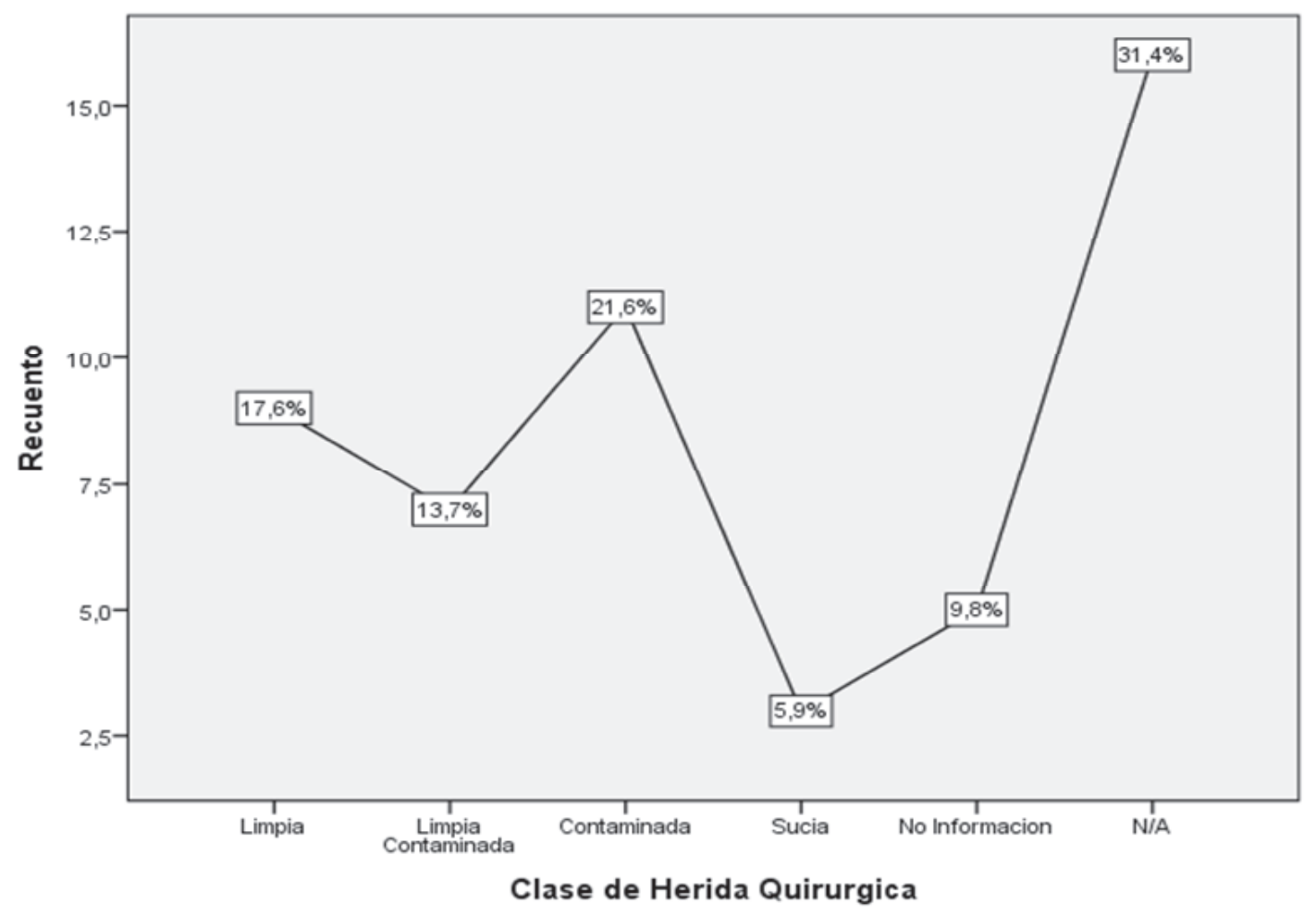

Gráfica 2: Tipo de herida según intervención quirúrgica. 
Según la clasificación de las heridas, del total de las incluidas en el estudio, el 68.6\%, pertenecieron a una intervención quirúrgica de las cuales $17.6 \%$ fueron limpias; $13.7 \%$, limpia contaminada; $21.6 \%$, contaminada; $5.9 \%$, sucia; $9.8 \%$, sin dato diligenciado en la hoja quirúrgica. Y el 31.4\% no corresponden a este tipo de herida (Quirúrgica). (Ver Grafica 2)

La distribución de las heridas, según el diagnóstico del paciente por especialidades quirúrgicas, fue así; del $54.9 \%$ de cirugía correspondieron a $13.7 \%$, apendicitis - peritonitis; $3.9 \%$ a fístulas, $11.8 \%$ a laparotomía, $5.9 \%$ a colecistectomía, $9.8 \%$ a toracostomía, $3.9 \%$ a lavado quirúrgico, $3.9 \%$ herniorrafía, $2.0 \%$ tiroidectomía. Del $21.6 \%$ ortopedia se distribuyeron así: $11.8 \%$ de fracturas - traumas, $7.8 \%$ de osteosíntesis; $2.0 \%$ de osteomielitis. Del $11.8 \%$, de medicina interna, se distribuyeron así: $9.8 \%$ de úlceras, $2.0 \%$ de drenaje de absceso cutáneo. De urología, que correspondió un total del 4.0\%: $2.0 \%$ de pieloplastia, $2.0 \%$ de prostatectomia. Del $4.0 \%$, de neurocirugía: $2.0 \%$ correspondió a absceso vertebral, $2.0 \%$ a contusión, y por cirugía plástica, $3.7 \%: 2.0 \%$ por simetrizacion facial y $1.7 \%$, por injerto. En lo referente a la localización según región anatómica, se encontró: $6 \%$, ubicadas en cabeza y cuello; $63,2 \%$, en la región toracoabdominal; $27,6 \%$, en miembros inferiores y un 4,0\%, en miembros superiores (ver cuadro 1 ).

Cuadro 1 Localización por región anatómica verificar tabla

\begin{tabular}{|c|c|c|c|}
\hline Región anatómica & & Frecuencia & Porcentaje \\
\hline \multirow{4}{*}{ Cabeza y cuello } & Cabeza Lat. Derecha & 1 & $2,0 \%$ \\
\hline & Cabeza Lat. Izquierda & 1 & $2,0 \%$ \\
\hline & Cuello Anterior & 1 & $2,0 \%$ \\
\hline & Dorso & 1 & $2,0 \%$ \\
\hline \multirow{7}{*}{ Región - toraco-abdominal } & Dorso Lat. Derecho & 1 & $2,0 \%$ \\
\hline & Abdomen & 21 & $41,2 \%$ \\
\hline & Abdomen Lat. Derecho & 2 & $4,0 \%$ \\
\hline & Abdomen Lat. Izquierdo & 1 & $2,0 \%$ \\
\hline & Cadera Lat. Derecho & 1 & $2,0 \%$ \\
\hline & Cadera Lat. Izquierda & 1 & $2,0 \%$ \\
\hline & Tórax Lat. Derecho & 2 & $4,0 \%$ \\
\hline \multirow{9}{*}{ Región - Miembros Inferiores } & Tórax Lat. Izquierdo & 2 & $4,0 \%$ \\
\hline & Glúteo & 3 & $5,8 \%$ \\
\hline & Muslo Anterior & 1 & $2,0 \%$ \\
\hline & Muslo Posterior & 1 & $2,0 \%$ \\
\hline & Rodilla Anterior & 1 & $2,0 \%$ \\
\hline & Pierna Anterior & 4 & $7,8 \%$ \\
\hline & Pierna Posterior & 1 & $2,0 \%$ \\
\hline & Pierna Anteroposterior & 1 & $2,0 \%$ \\
\hline & Dorso Pie & 2 & $4,0 \%$ \\
\hline \multirow{2}{*}{$\begin{array}{l}\text { Región Anatómica - Miembros } \\
\text { Superiores }\end{array}$} & Antebrazo Anterior & 1 & $2,0 \%$ \\
\hline & Antebrazo Lateral & 1 & $2,0 \%$ \\
\hline
\end{tabular}

En el cuidado de las heridas, se debe tener presente su etiología y tratar de preservarlas lo más alejado de la infección, máxime cuando las infecciones asociadas a la atención en salud, también llamadas hospitalarias, son un problema creciente y actualmente se perfilan en el mundo como una amenaza para la salud pública, superando como causa de muerte al VIH-SIDA, el cáncer de mama o los accidentes de tránsito (8)
Entendido así la infección asociada a la atención en salud (IAAS), conocida como nosocomial, como aquella localizada o sistémica que resulta como una reacción adversa a la presencia de un agente infeccioso o su toxina y que no estaba presente, ni en periodo de incubación, ni al ingreso del paciente al hospital. 


\section{Procedimientos desarrollados en el manejo de las heridas: Evidencias.}

A través de los resultados de esta investigación, se pudieron apreciar las diferentes formas de realizar el procedimiento del cuidado de los pacientes con diferentes heridas, en cuanto a la técnica, los materiales e insumos utilizados durante el proceso de curación. En el contexto del cuidado de la herida, es relevante que al establecer una relación entre la enfermera y el paciente, esté mediada por la comunicación, la cual debe iniciar con la explicación del procedimiento al usuario y, de ser posible, a su acompañante, quien se convertirá en su cuidador en casa. En esta investigación, se encontró que en el $33.3 \%$ de los pacientes valorados se evidenció este proceso, no presentándose en el $66.7 \%$ restante. Otro aspecto fundamental en el cuidado del paciente con herida y que contribuye de igual forma a establecer una relación adecuada con el personal de salud, es la privacidad del paciente, uso de los biombos, cubrir con sábanas, entre otros. Al valorar si se tiene en cuenta este aspecto, se encontró que en el $17.6 \%$ sí realizan acciones para propender por la intimidad y el $82.4 \%$, no. Orem (4), concibe al ser humano como un organismo biológico, racional y pensante; como tal es afectado por el entorno y es capaz de desarrollar acciones que le afecten a él mismo, o a otros o a su entorno, condiciones que le hacen capaz de llevar a cabo su proceso de autocuidado. En este mismo sentido, en el cuidado de las heridas existen procesos básicos como el procedimiento del lavado de manos antes y después del contacto con las heridas. Según protocolo institucional, se evidenció el cumplimiento en un $19.6 \%$ y el no cumplimiento en el $80.4 \%$, lo cual se convierte en un riesgo potencial de infecciones cruzadas. En el año 2004, la Organización Mundial de la Salud, OMS, presentó una iniciativa para mejorar la seguridad del paciente y publicó directrices sobre la higiene de las manos en la atención sanitaria, bajo el lema: "una atención limpia es una atención más segura". (10)" La promoción de la higiene de las manos reduce las infecciones, por lo que permite salvar vidas y reducir la morbilidad y los costos relacionados con las infecciones asociadas a la atención sanitaria".

Adicional a lo anterior y con relación al proceso de cuidado de pacientes que presentan heridas, es fundamental contar con materiales e insumos adecuados en cantidad, calidad y organización. En esta investigación se evidenció que en el $80.4 \%$ se cuenta con ello; mientras que un $19.6 \%$, no. Con relación a la utilización de elementos de bioseguridad por parte del personal que realiza el procedimiento se encontró que $2.0 \%$ utilizan tapabocas; $3.9 \%$, guantes; $80.4 \%$, tapabocas y guantes; $2.0 \%$, tapabocas y guantes estériles; $2.0 \%$, tapabocas, guantes, blusa y gafas; $7.8 \%$, tapabocas, blusa, guantes y $2.0 \%$ tapabocas, gorro y guantes. Esto se puede relacionar con que la IPS no cuente con suficientes implementos de protección o que no se halla establecido un proceso de sensibilización frente al autocuidado, lo que posibilita un aumento en el riesgo biológico.

De acuerdo con la norma de procedimientos básicos y de asepsia, es posible realizar el cuidado de la herida con la técnica de una sola mano, dependiendo de la complejidad de la curación. Para este estudio se evidenció que esta práctica fue de un 51\%; se realizó con la técnica de dos manos y la participación de una persona "circulante", en un $37.3 \%$. Independiente de la técnica utilizada, es necesario cumplir con los requerimientos de una adecuada asepsia, considerando la posibilidad de que el cuidador determine la experticia y conocimientos frente la necesidad de no promover las infecciones. En un estudio realizado por Ambota \& Caldera citada por Martínez, y otros, 2012(11), se identificaron conocimientos, actitudes y prácticas del personal de salud en el control de infecciones intrahospitalarias.

Con relación al proceso de la curación en el contexto del cuidado, éste se puede definir como aquella técnica que favorece el tejido de cicatrización. Es un proceso considerado natural y generalmente no requiere de tratamientos especiales, "existen heridas crónicas que no concluyen este proceso por diversos factores subyacentes, en estos casos es necesario intervenir, por ejemplo en las úlceras por presión, las úlceras vasculares y las heridas quirúrgicas que cierran por segunda intención" (12). Las heridas no complicadas solamente requieren en su cuidado que se apliquen técnicas que no se conviertan en factores que retrasen la cicatrización, esto incluye también el cuidado de la piel circundante. Para esta investigación, se encontró que el aflojar los esparadrapos o vendajes de sujeción, como parte del cuidado de la piel, un $76.5 \%$ del personal sí lo hace y un $11.8 \%$, no. Para esta actividad, se utilizan tijeras, sin desinfección entre pacientes, u hojas de bisturí; afectando la seguridad del paciente. Además se encontró que el retiro de material de la herida se realiza con guantes y medidas de protección 
en un $76.5 \%$ y el $13.7 \%$ no los utiliza.

Adicional a lo anterior, la irrigación de apósitos antes de ser retirados de la herida, proceso que a la vez que promueve la cicatrización y disminuye el dolor en el paciente. Se realizó en un $25.5 \%$ y no se tuvo en cuenta esta actividad en un $45.1 \%$, mientras que el $29.4 \%$ no lo requiere por las particularidades de la herida. En algunos casos, el paciente lo realiza en la ducha.

Otro factor que determina un proceso adecuado de cicatrización, se relaciona con los materiales utilizados en el primer barrido sobre la herida, el cual debe ser realizado con materiales isotónicos, En este sentido, se encontró que para este procedimiento se utilizó agua común en un $2.0 \%$; solución salina normal, $68.6 \%$, y alcohol, 29.4\%. Durante el procedimiento de la curación se realizó irrigación de la herida en un $13.7 \%$ con $\mathrm{SSN}$, el $45.1 \%$ no lo realiza y el 41.2 no requería irrigación. De los que la irrigaron, el 5,9\% utiliza la riñonera para recibir el drenaje de la herida y el $94.1 \%$, no. La técnica utilizada para la limpieza de la herida fue con fricción de los pulpejos, dedos enguantados, en un $2.0 \%$; con gasas, $90.2 \%$; con apósitos, $5.9 \%$, y un $2.0 \%$ no friccionó la herida. Desde la forma en la que se realiza el barrido circular de la herida, se encontró que un $27.5 \%$ lo realiza hacia adentro; $5.9 \%$, hacia afuera; $64.7 \%$, adentro y afuera y $2.0 \%$, arriba y abajo. En relación con el secado con gasa del área circundante de la herida se encontró que el 47.1 lo hace y un $52.9 \%$, no. La utilización de la técnica aséptica en general durante el desarrollo de todo el proceso de curación de la herida es aplicada por un $64.7 \%$, mientras que el $35.3 \%$ no hace uso de ella. El material primario utilizado para cubrir la herida fue $11.8 \%$ con apósito especial; $29.4 \%$, gasa; $3.9 \%$, gasa rollo; $25.5 \%$, apósito y $29.4 \%$, no utilizó.

Con relación al uso de protección secundaria sobre la primaria, el 3.9\% utilizó apósito; el 9.8\%, apósito especial; $15.7 \%$, gasa en rollo; $3.9 \%$, algodón laminado; $2 \%$, vendaje elástico y el $64.7 \%$, ninguno. Con respecto a la sujeción del material secundario, un $47.1 \%$ lo efectúa con esparadrapo de tela; $3.9 \%$, con micropore; $2 \%$, con vendaje gasa; $5.9 \%$, con vendaje elástico; $7.8 \%$, con sábana; $2 \%$ con Fixomull ${ }^{\circledR} \mathrm{y}$ el $23.5 \%$ no utilizó.

Hasta hace poco tiempo el cuidado de las heridas se centraba especialmente en un tratamiento de protección de las mismas con diversos materiales como antisépticos, gasa, apósitos absorbentes, entre otros, pero a través de los años esto se ha modificado, por lo que existen en la actualidad insumos, materiales y métodos de curación indicados para cada tipo de herida. (12)

En cuanto a quién realiza el procedimiento de la curación de la herida, se encontró que el $82.4 \%$ lo realiza la auxiliar de enfermería; $9.8 \%$, la enfermera, 3.9\%, estudiante de enfermería profesional y el $3.9 \%$, estudiante de la escuela de auxiliares de enfermería.

Al indagar acerca del confort del paciente después del procedimiento, se halló que el $76.5 \%$ del personal lo verifica; con relación a la comunicación con el paciente un $23.5 \%$ del personal notificó al paciente sobre el estado de su herida. El registro del procedimiento en la Historia Clínica, HC, fundamental para el seguimiento efectivo del proceso; se identificó que un $25.5 \%$ del personal elaboró la nota de enfermería describiendo la herida en su evolución, tolerancia del paciente al procedimiento y su satisfacción, un 35.3\% la elaboró parcialmente y un 39.2\% no la realizó. Jean Watson (3) afirma que los cuidados en nuestra cultura y tiempos actuales necesitan una fuerte reconsideración hacia la humanización de la salud, en la que los cuidados se sitúan ética y profesionalmente esto hace referencia en este caso al registro de los procedimientos como elemento fundamental que garantiza la continuidad del cuidado.

Para el cuidado de las heridas se requiere permitir periodos de descanso que mitiguen los estresores durante los procedimientos, en esta investigación se evidenció que el $21.6 \%$ si daban estos espacios; en este sentido lo que concierne al empleo de la técnica de imaginación guiada para mejorar el dolor como respiración profunda, exhalación lenta, pensamientos positivos y rememorativos se percibió que un $2.0 \%$ lo proporcionó. Con relación a la aplicación de la escala análoga para el dolor Eva; un 7.8\% lo empleó. En lo referente a permitirle al paciente acompañante durante el procedimiento, un $9.8 \%$ lo permitió. En los incentivos que propenden por el apoyo emocional como parte del cuidado se encontró que un $11.8 \%$ motivó al paciente. Al indagar acerca de los procesos educativos un hallazgo fue que el $23.5 \%$ ofreció educación al paciente y/o cuidador sobre el manejo de la herida.

De otra parte, con relación a la disposición final del material de desecho utilizado durante la curación, se observó el uso de una bolsa roja pequeña, hasta que se llena; no se usa para cada curación, según protocolo institucional; y al observar el desecho adecuado se- 
guido al procedimiento de curación, se encontró que el $76,5 \%$ sí lo realiza, mientras que el $23.5 \%$, no. Al valorar si el equipo utilizado se deja en orden al finalizar el procedimiento el $47.1 \%$ del personal lo hace. A continuación se presenta la valoración realizada a las heridas durante el procedimiento de curación desde su clasificación, complejidad, características del lecho, piel circundante, secreción, y signos de infección.
Dentro de las características de las heridas post quirúrgica se encontró que el $45.1 \%$ era cerrada; el 17.6\%, abierta; el 3.9\%, suturada; el 17.6\%, cerrada suturada; $2 \%$, fístula; el $2 \%$ con absceso, el $2 \%$ con tutor externo, el $3.9 \%$ orificio cutáneo y el $5.9 \%$ no aplica. (Ver grafica 3)

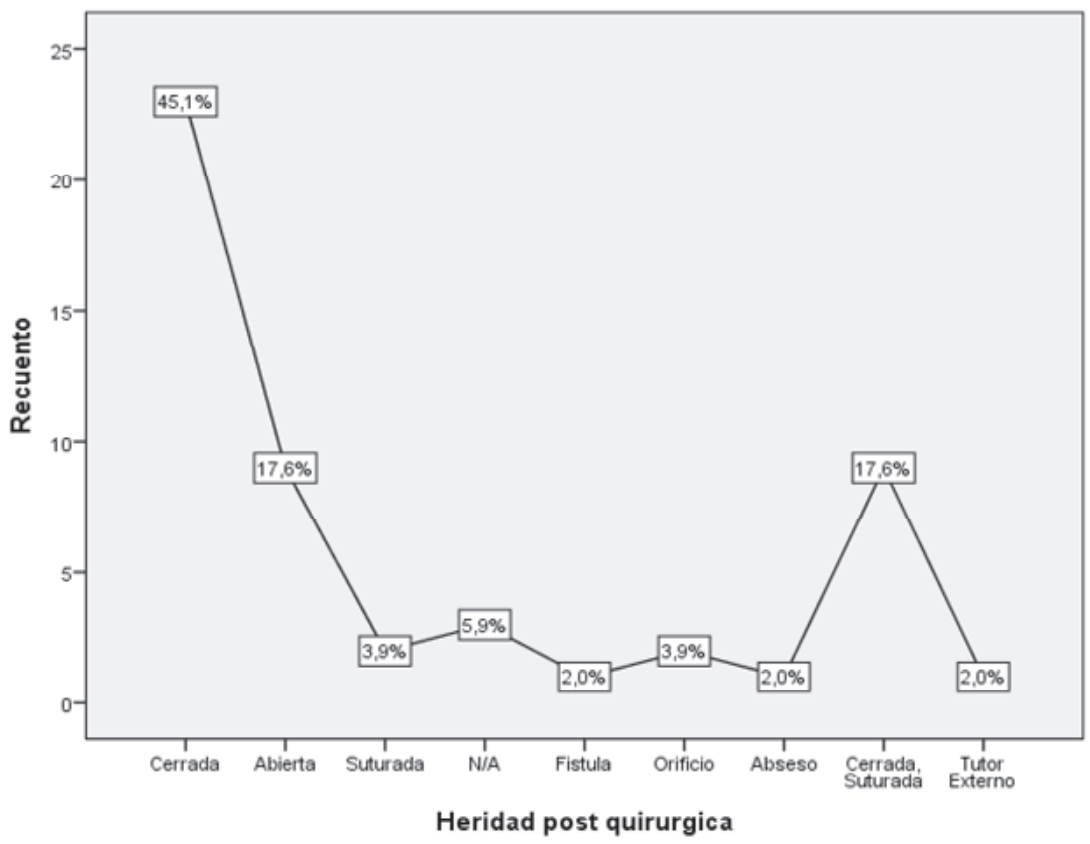

Gráfica 3: Características de las heridas post quirúrgica

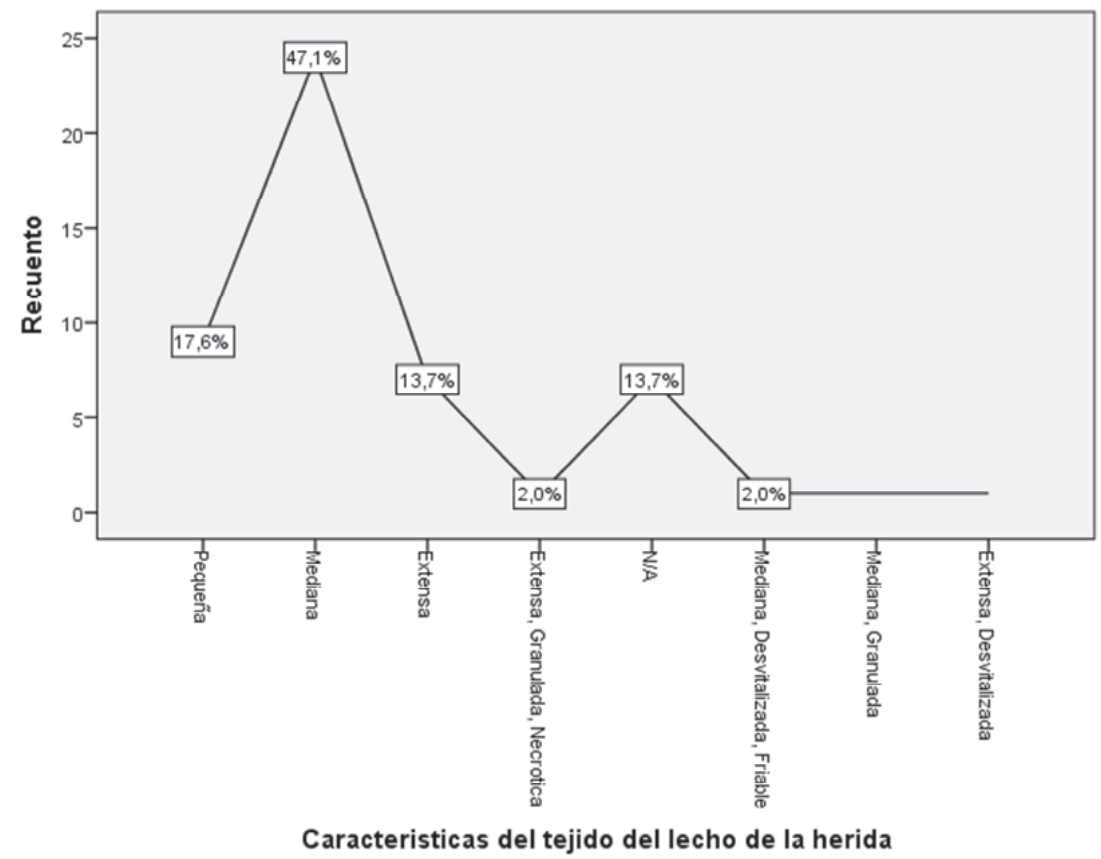

Gráfica 4: Características Del Lecho De La Herida 
Al valorar el grado de complejidad de la herida se encontró que el $52.9 \%$ no lo es, el $2 \%$ corresponde a contenida, el 3.9\% con bolsa de Viaflex ${ }^{\circledR}$; el 2\%, evisceración con Viaflex ${ }^{\circledR}$; el 2\%, sutura; el 3.9\%, contenida con Viaflex ${ }^{\circledR}$; el 5.9\%, Dren de Penrrose; el $2 \%$, Hemovac; el $25.5 \%$ no aplica.

La cicatrización de las heridas es un proceso natural que normalmente no requiere de tratamientos especiales; sin embargo, existen heridas crónicas o complejas que no cicatrizan debido a la existencia de factores subyacentes, en estos casos es necesario intervenir (12)

Un elemento fundamental en la evolución de la herida está determinado por las características del lecho de ésta. Se encontró que el $17.6 \%$ es pequeño; el $47.1 \%$, mediano; el $13.7 \%$, extensa; el $2 \%$, necrótico; $2 \%$, friable; $2 \%$, granulado; $2 \%$, desvitalizado y el $13.7 \%$ no aplica. (Ver grafica 4)

Según los estados bacterianos del lecho de la herida se encontró que el $11.8 \%$ estaba contaminado; el 3.9\%, colonizado; el 52.9\% ningúno y el 31.4\% no aplica. La valoración y posterior preparación del lecho de la herida es un modelo cambiante que engloba el tratamiento de la causa y se enfoca en tres componen- tes del cuidado de heridas: desbridamiento, apósitos interactivos de ambiente húmedo y equilibrio bacteriológico" (13). Un enfoque integral del control del exudado, llevará a tratar los factores subyacentes y a asegurar que el entorno de la herida se mantenga húmedo. Un ambiente húmedo en la herida es aquel que contiene el nivel óptimo de humedad para permitir la división y migración celular, a la vez que asegura que el lecho de la herida no se reseque o esté mojado en exceso. En ambiente húmedo la síntesis de colágeno y la formación del tejido de granulación mejoran; la migración celular y el revestimiento epitelial son más rápidos y no aparecen escaras, esfacelos o costras. (14) En la valoración de la piel circundante se determinó que en un $54.9 \%$ estaba hidratada; el $19.6 \%$, seca; el $2 \%$, violeta; el $2 \%$, seca violeta; el $3.9 \%$ presentaba dermatitis, el $2 \%$ era pustulosa y el $15.7 \%$ no aplica.

Con referencia a las características de la secreción, se encontró que el $11.8 \%$ era serosa; el 19.6\%, sanguinolenta; el $19.6 \%$, no presentaban; el $2 \%$, purulenta; el $2 \%$, sanguinolenta purulenta y el $45.1 \%$ no aplica (ver Gráfica 5). Con relación a los bordes de la herida, el $64.7 \%$ era regular y el $35.3 \%$, irregular. El olor característico de las heridas fue en un $17.6 \%$ inoloro; el $9.8 \%$, fétido; el 54.9 , ninguno y el $17.6 \%$ no aplica.

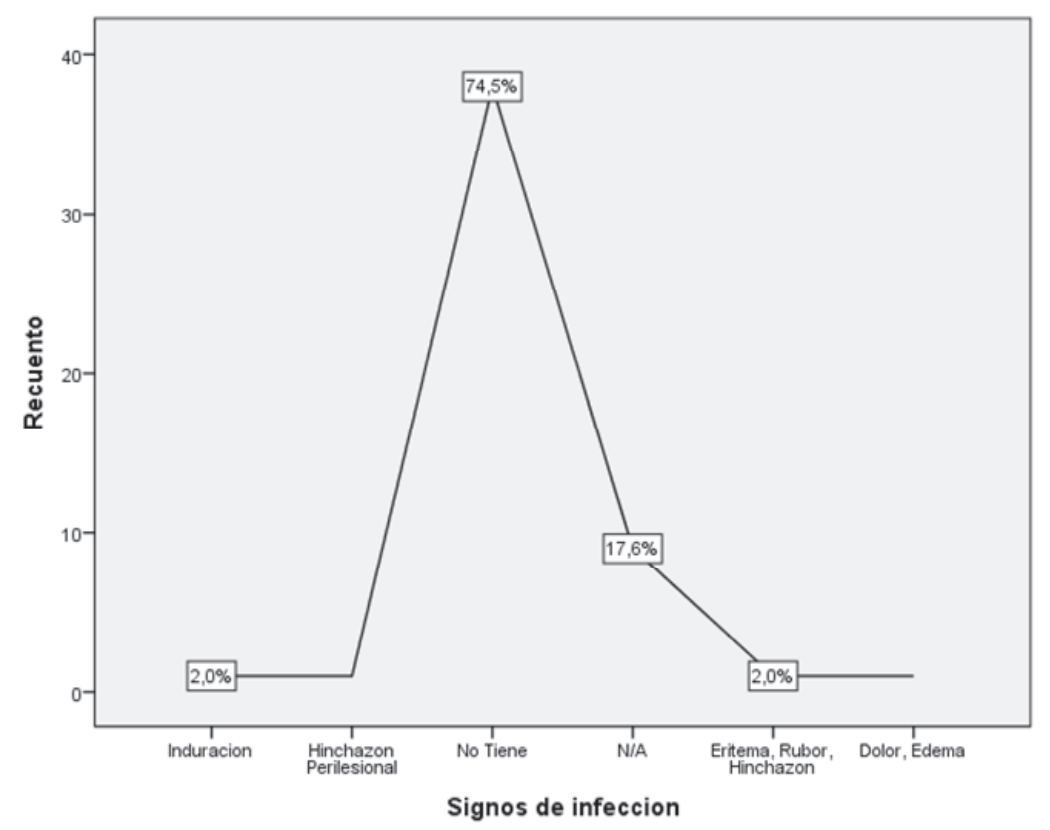

Gráfica 5: Presencia de signos de infección 
De acuerdo con el exudado, el $17.6 \%$ presentaba poco; el $7.8 \%$, insuficiente; el $2 \%$, exudado abundante; el $45.1 \%$, ninguno y el $27.5 \%$ no aplica. En relación a la consistencia del exudado el $9.8 \%$ era líquido; el $3.9 \%$, denso; el 3.9\%, transparente; el $45.1 \%$, ninguno y el $37.3 \%$ no aplica. En cuanto el color el $13.7 \%$ era amarillo; el 2\%, chocolatoso; el 60.8\%, ninguno y el $23.5 \%$ no aplica.

Con relación a la presencia de signos de infección el 2\% presentaba induración; el 2\%, hinchazón perilesional; el 2\%, eritema - rubor- hinchazón; el 2\%, dolor - edema; el $74.5 \%$ no presentó y el $17.6 \%$ no aplica.

Según registro en la historia clínica se encontró que al $23.5 \%$ de los pacientes se les tomó gram y cultivo, y un $76.5 \%$ no; y a los pacientes que se les realizó lavado quirúrgico, al $15.7 \%$ se les realizó gram y cultivo.

Los factores de riesgo que originan infección del sitio quirúrgico pueden prolongar la estancia hospitalaria pre y posquirúrgica, la prescripción no fundamentada de antimicrobianos, la deficiente limpieza antiséptica de la piel del paciente antes de la cirugía, y otros descuidos insalubres. Los factores intrínsecos de los pacientes son: la complejidad de sus enfermedades, el estado nutricional, el tabaquismo, la obesidad, y la vejez. $(15,16,17)$

En esta investigación, se encontró que los factores que más afectaron a los pacientes fueron: $9.5 \%$, hipertensión y estancia hospitalaria prolongadas; $8.3 \%$, diabetes; $7.1 \%$, consumo de SPA; $4.8 \%$, desnutrición, procesos vasculares o anemia y un $3.6 \%$, enfermedades mentales. También se encontró $2.9 \%$ de neoplasias y el $2.4 \%$, enfermedades nosocomiales, intervenciones quirúrgicas prolongadas, insuficiencia renal crónica, abandono social y tabaquismo. Por último, se evidenció el $1.2 \%$ deshidratación, enfermedades cardiovasculares, EPOC, osteomielitis, estado postnutricional, convulsiones, dislipidemias, osteosíntesis anteriores y esplenomegalia y un $21.4 \%$ no tiene antecedentes. (ver grafica 6)

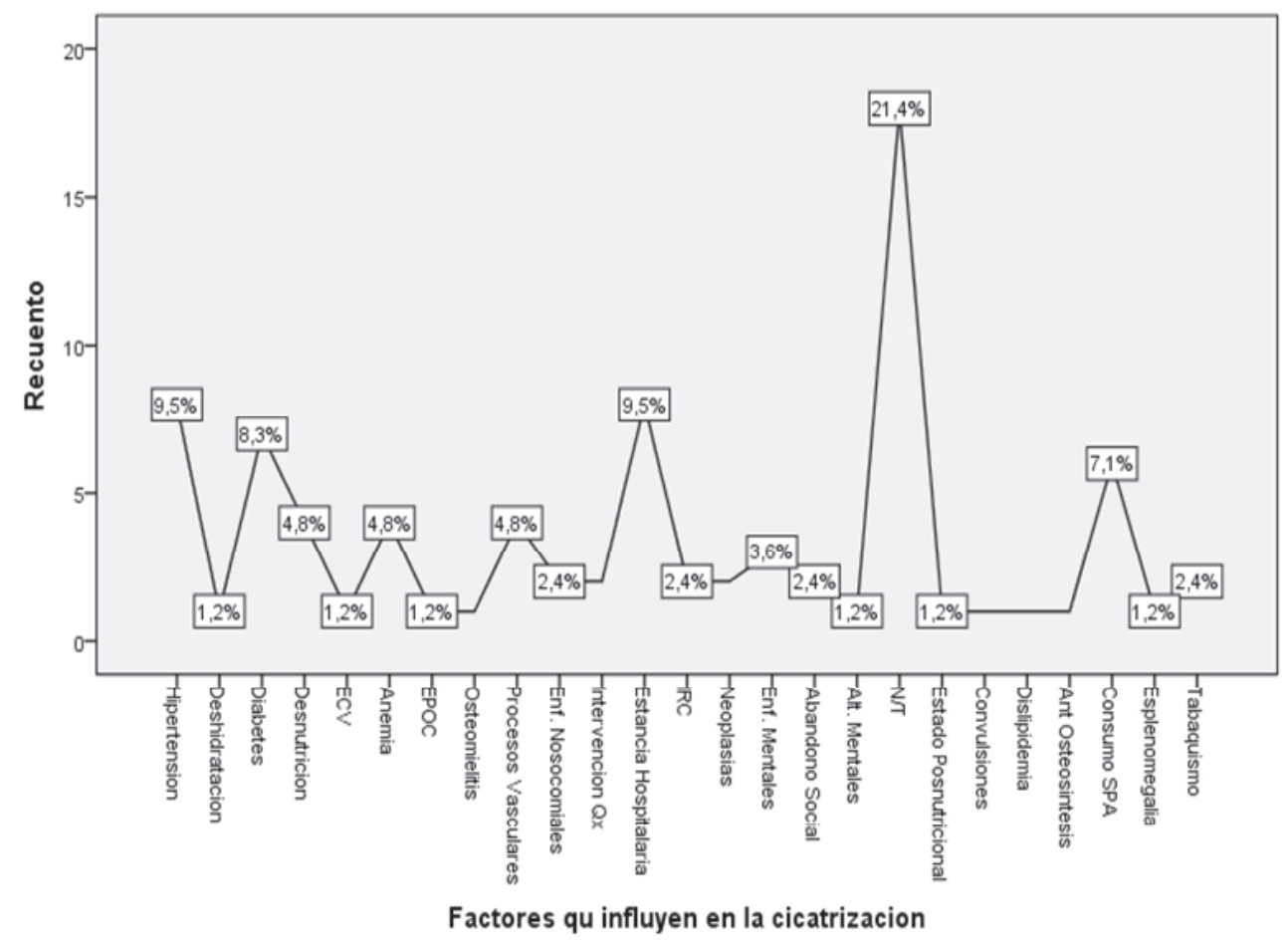

Gráfica 6: Factores Influyen en el Proceso de Cicatrización (pacientes de la investigación) 
Por todo lo anterior, las enfermedades concomitantes en muchos procesos patológicos tienen un efecto negativo en la cicatrización de heridas. Por ejemplo, la reparación tisular requiere oxígeno y los factores que reducen la disponibilidad como son las enfermedades cardíacas, anemia o desordenes respiratorios crónicos, pueden retardar el proceso de cicatrización. Los accidentes cerebro vasculares y espinales, así como fracturas femorales pueden reducir la sensibilidad y / o movilidad incrementando el riesgo de lesiones por presión. La artritis reumatoide está asociada a un aumento del riesgo de ulceración siendo una enfermedad que puede complicar la evolución de la herida. El proceso de la diabetes mellitus asociada a una neuropatía periférica y arteriosclerosis incrementa el riesgo de ulceración. La diabetes puede causar un retraso en la cicatrización de heridas debido a los niveles de colágeno, función y quimiotaxis granulocítica defectuosa y la reducida angiogénesis. (Silhi, 1998)

\section{Materiales e insumos en el cuidado de la herida de los pacientes.}

Un aspecto importante en el proceso del cuidado de las heridas se relaciona con los materiales e insumos que se utilizan sobre estas y la piel circundante, estos aspectos valorados en la investigación, son presentados a continuación.

Los profesionales de la salud cuentan actualmente con la oferta de apósitos más amplia de la historia; si bien esto beneficia potencialmente al paciente también puede ser, para el profesional, una dificultad a la hora de elegir la mejor opción en cada caso $(18,19)$. Hace cincuenta años la elección de materiales e insumos a la hora de curar las heridas se centraba básicamente en el tipo de gasa a utilizar: seca, mojada o parafinada. Ahora, existe tal variedad y combinación de apósitos y tecnologías que enfermeras y médicos pueden llegar a dudar sobre qué deben utilizar, por qué y cuándo, sino cuentan con una capacitación adecuada al respecto. $(19,20)$

En esta investigación, en cuanto a los materiales e insumos utilizados para el cuidado de las heridas, clasificados en barrido de la herida, limpieza y secado, antibióticos tópicos, antisépticos, estimuladores de tejido, protección, fijación y otros materiales de apoyo, se encontró:

Para barrido de la herida: solución salina normal, agua estéril, aguas duras (ducha).Limpieza y secado: Gasa, apósito, apósito especial, gasa en rollo, guantes estériles, guantes limpios. Antibiótico tópico: Furacín. Antisépticos: alcohol al 70\%, clorhexidina al 2\%.Estimuladores de tejido: colágenas, Tritricum vulgare al 2\%. Protección: apósito, apósito especial, gasa, algodón laminado y vendaje elástico. Fijación: esparadrapo de tela, micropore, Fixomull. Otros: polivinilo (Viaflex), baja lenguas, aplicadores, sonda nelatón, jeringas, bisturí, xilocaina spray, vaselina, bolsas de residuos, riñonera. (ver grafica 7)

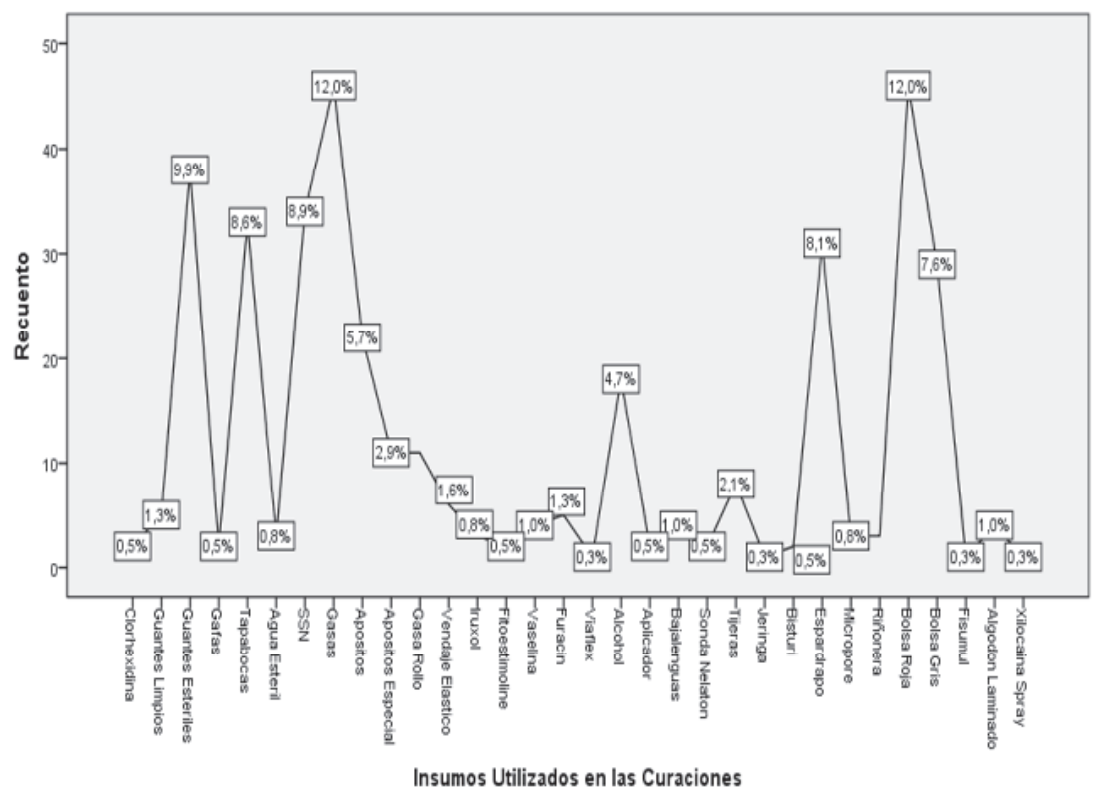

Gráfica 7: materiales e insumos utilizados para la curación de las heridas 
Estos materiales e insumos son utilizados de forma indiscriminada para los diferentes tipos de heridas.

Mengarelli, R. H., y otros en el 2013(21), con relación a la utilización de antisépticos en heridas crónicas afirman que históricamente han sido considerados como un elemento fundamental en su manejo, y estos se utilizaban indiscriminadamente durante las curaciones, desbridamiento o previo a cualquier tipo de tratamiento; en la actualidad se conoce que el uso frecuente de los antisépticos sobre las heridas tiene efectos deletéreos, sobre todo en heridas crónicas. Uno de los antisépticos más conocidos y empleado es el alcohol, "no debe ser empleados en heridas agudas o crónicas" ya que produce una fuerte irritación y dolor, precipita las proteínas y forma coágulos que favorece el crecimiento bacteriano. (21)

Adicional a lo anterior, se reconoce en la actualidad que los antisépticos pueden producir la muerte o inhibición celular de las bacterias, a través de oxidación, hidrolisis o inactivación de enzimas, con pérdida de los constituyentes celulares (22). Es indicado generar protocolos para contribuir con la estandarización no solamente del uso de los antisépticos, sino a la vez el control de infecciones.

Es evidente que el establecimiento de protocolos tiene como meta trabajar sobre la estandarización de procesos, los cuales deben ser de cumplimiento obligatorio para la seguridad de sus pacientes y reducir las infecciones nosocomiales. Un paciente con infección del sitio quirúrgico tiene cinco veces más riesgo de morir que un paciente en la misma condición no infectado; adicional a lo anterior, cada infección en el sitio quirúrgico provoca que el paciente esté como mínimo, una semana más en el hospital con respecto a lo previsto, lo que deriva en gastos adicionales y, además, la pérdida de la expectativa de salud puesta en el propio procedimiento quirúrgico (23)

A lo largo de la historia de la curación de heridas, las personas han intentado entender y definir el concepto de infección de una herida. Los resultados de las heridas infectadas se observaron mucho antes de que se identificasen las causas y hubo un tiempo en que algunos síntomas de infección se consideraron un sig- no de curación (24). Hasta en nuestra época moderna de la medicina, aún nos queda mucho por discutir sobre cómo identificar y describir la infección, con los nuevos conceptos y teorías que se han desarrollado recientemente $(25,26)$

Una forma de controlar la infección a nivel institucional es el establecimiento de protocolos que propendan por el cuidado de la herida de tal forma que a la vez que estimulan los procesos de cicatrización natural controlen la complicación de estas, infección. En el protocolo institucional del contexto de esta investigación se contempla que cuando un paciente presenta una herida quirúrgica cerrada, ésta debe permanecer cubierta las primeras 24 horas; después de este tiempo, se realiza limpieza durante el baño con agua y jabón y se deja descubierta. Si la herida está cubierta con cinta, micropore, ésta no se retira hasta que se encuentre visiblemente sucia o se desprenda espontáneamente. Al valorar esta situación se encontró que en el $29.4 \%$ el personal cumplió, el $31.4 \%$ no, y el 39.2\% no presentaban heridas de esta tipología.

El protocolo, en cuento a la presencia de una herida quirúrgica abierta, plantea que al día siguiente de ser intervenida se irrigue con abundante solución salina y se deje cubierta, no empacada. El procedimiento se debe realizar en la cama del paciente, no trasladar al baño, proteger la cama y los tendidos del drenaje del líquido utilizado en la irrigación, y dejar seco el paciente. Si se dejó Viaflex fijado con sutura, se limpian los bordes y se protege la piel circundante, protectora cutánea, y se deja cubierta con un apósito especial estéril, no se debe irrigar excepto que tenga sellamiento del tejido de granulación, protegiendo la piel circundante, dejar cubierta con un apósito especial estéril. En este sentido, se pudo apreciar que el protocolo fue cumplido en un $5.9 \%$ por el personal y en un 33.3\% no, para el $60.8 \%$ no corresponde al tipo de herida.

Con relación al manejo del paciente con una herida cerrada en reemplazo de cadera, el protocolo estipula que esta se debe destapar a las 24 horas, limpiar con alcohol $70 \%$ o clorhexidina $2.0 \%$, Isopañin, y volver a cubrir. Este procedimiento no se ejecutó correctamente en el único paciente de la investigación que presentaba este tipo de herida. (Ver grafica 8) 


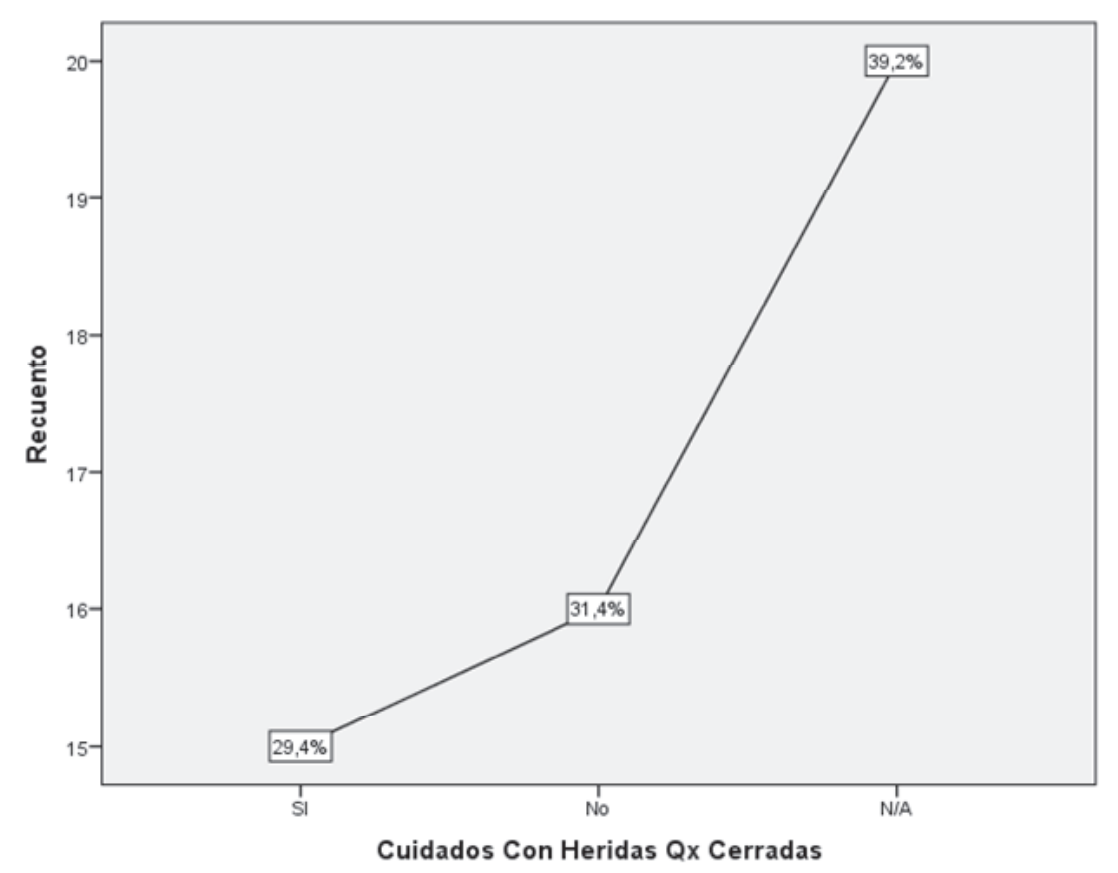

Gráfica 8: Porcentaje de cumplimiento protocolo institucional- herida quirúrgica cerrada.

El elegir el apósito correcto para la herida de un paciente es un proceso significativo; esto puede ser considerablemente fácil si se tienen los conocimientos, experiencia y un sistema lógico de valoración de la herida, al mismo tiempo comprender el contexto y desarrollo de los apósitos modernos, los cuales presentan diferentes categorías dependiendo de los materiales con los cuales se preparan; a partir de toda esta información, se está capacitado para elegir el apósito adecuado para la herida del paciente. (27).

Para la situación en la que el paciente presenta heridas profundas, en el 3.9\% de las situaciones de la investigación se cumplió con el protocolo el cual dice que se lavan con sonda nelatón y solución salina para irrigar su interior, en el $25.5 \%$ de los casos no se cumplió el protocolo y en el $70.6 \%$ no aplicó debido a las características de la herida.

En el caso que el paciente presente varias heridas, según protocolo, se inicia la curación por la herida más limpia, y la curación de la herida infectada es la última que debe realizarse, para esta investigación este componente fue tenido en cuenta en un $19.6 \%$, en un $31.4 \%$ no y el $49 \%$ no aplica por las características propias del paciente.

Con relación a la fijación del material sobre la herida el protocolo institucional plantea que se puede usar vaselina en el apósito, para evitar que éste se adhiera de forma inadecuada y dolorosa; además, que ofrece humedad al tejido necesario para el proceso de cicatrización. En la investigación se pudo observar que este procedimiento se realizó en un el 7.8\%, 84.3\% no lo efectuó y en el 7.8\% no aplica.

El protocolo registra que las heridas no deben ser secadas en su interior; lo cual pudo ser observado en un el $92.2 \%$. Cuando los pacientes presenten inserción de tutores, los sitios de inserción deben ser limpiados y desinfectados diariamente con alcohol, eso se pudo apreciar en el $3.9 \%$, y en el $13.7 \%$ no. Para un $82.4 \%$ no aplica por las características de la herida.

En cuanto a la toma de cultivos en el caso de que un paciente lo requiera, el protocolo estipula que debe lavarse muy bien la herida con solución salina y luego utilizar aplicador estéril para tomar la muestra de la parte más profunda de la herida utilizando técnica aséptica estricta, guantes estériles, tapabocas, lavado de manos o fricción de manos con alcohol glicerinado. El aplicador debe venir en doble envoltura, se debe manipular la envoltura interna con guantes y al tomar la muestra inmediatamente introducirlo al tubo de laboratorio y enviarlo. En relación con el procedimiento mencionado, al revisar la historia clínica se encontró que fueron tomados en un $23.5 \%$ de los pacientes, no se registra el cómo fueron realizados los 
procedimientos.

\section{EI momento de realizar el cuidado del paciente con heridas: rituales}

En lo que se refiere a la manifestación de un ritual antes de iniciar el procedimiento por parte de las personal, en esta investigación se encontró que el 5.9\% lo realiza y el $94.1 \%$ no. Cada trabajador del personal de salud, dentro de sus creencias, puede o no invocar un ser supremo que lo ilumine sin tener que verbalizar su mismidad que incida en mostrar un ritual evidente que nos diga su creencia, por naturaleza siempre se piensa que nos va ir muy bien en nuestro actuar. Jean Watson (3) pide unir la ciencia con las humanidades para que las personas que brindan cuidado tengan un sólido fondo artístico liberal y entiendan otras culturas como requisito para utilizar la ciencia del cuidado, integrando la mente - el cuerpo - y el espíritu. El desarrollo continuo personal y profesional, el crecimiento espiritual, y la práctica espiritual personal ayudan a los cuidadores a entrar en este nivel más profundo de la práctica de curación profesional que permite descubrir una condición transpersonal del mundo y una actualización más extensa de las "competencias ontológicas necesarias" en este nivel de práctica avanzada de la enfermería (28).

Las intervenciones de los agentes de salud permiten establecer relaciones de afecto, confianza y seguridad. En este orden de ideas, el contacto físico como abrazar, apretar la mano, coger al otro amorosamente, se convierten en manifestaciones de afecto, intencionalidad y ternura, traducidos muchas veces en rituales de la práctica de cuidado.

El contacto fisico es una forma de comunicación amorosa. La persona recibe sentimientos de apoyo, seguridad y confianza que le hacen posible afrontar la crisis del momento. Los silencios, gestos y otras formas de lenguaje no verbal, transmiten más que las palabras; la accion concreta del hacer.Los profesionales de la salud se preocupan por la persona como un ser totalitario, holistico y no unicamente la persona como un conjunto de partes o procesos. Hablar de la totalidad del ser y del cuidado de la persona desde esta perspectiva promueve la integralidad. Es reconocer la condicion de persona en el otro, como un ser único, dotado de caracteristicas propias y particularidades; un ser digno y libre. (29)

\section{CONCLUSIONES}

Las heridas en los pacientes del estudio se caracterizaron por que en su mayoría fueron producidas por trauma, en la especialidad de cirugía general, toracoabdominal, y ortopedia, la distribucion fue equitativa entre abierta y cerrada, la mayoría agudas y se presentan indiscriminadamente en todas las edades y sexos.

Las técnicas y procesos desarrollados para el cuidado de las heridas son realizados dependiendo de las personas que ejecutan el procedimiento; no obstante la existencia de protocolos institucionales.

No existe un proceso estructurado de valoración integral de la herida que permita realizar una selección racional de los materiales e insumos requeridos según características particulares de la misma. Existe poca gestión ante la institución para contar con materiales e insumos acorde con los avances científicos. Adicional a esto, se registra un proceso deficiente en el seguimiento de la evolución de la herida y notas de enfermería, lo cual contribuiría a reorientar su cuidado según necesidad.

Se presenta poco la práctica de rituales que establezcan el proceso de cuidado de las heridas en un contexto de lo humano, lo cual redundaría en el establecimiento de lazos en los que se reconozcan los sentimientos y sensaciones del otro; esto es humanizar el cuidado de los pacientes con heridas.

\section{RECOMENDACIONES}

Humanizar y sensibilizar el cuidado del paciente con heridas por parte del personal de ENFERMERÍA y del grupo multidisciplinario, además involucrar al paciente y red de apoyo en su autocuidado.

Propender por la recuperación o el establecimiento del lidezgo por parte del profesional de ENFERMERÍA en sus delegaciones de actividades y monitorizacion del cumplimiento de ello.

Optimizar la dotacion de implementos de tecnología avanzada para disminuir largas estancias hospitalarias; insertando a la vida laboral al paciente lo mas pronto posible y reestableciendo los lazos familiares.

Desarrollar procesos de seguimiento y control que permitan monitorizar la adherencia a los protocolos 
institucionales y la practica profesional de ENFERMERÍA de forma idónea.

Propender por el establecimiento de contextos de cuidado de las personas de forma mas humanizada y acorde con las caracteristicas particulares de las necesidades de los usuarios.

\section{BIBLIOGRAFIA}

1. Falla J., Henao A. Efecto del polivinilo en el manejo de heridas abiertas en pacientes adultos de los servicios quirúrgicos del hospital San Juan de Dios de Armenia (Q). Cali: Universidad del Valle; 1995.

2. Harper E. Studies on the Mechanism of Action of Bacterial Collagenase in Collagenase. New York: Science Publishers, Inc. 1972.

3. Watson J. Caring Science as Sacred Science. Philadelphia: AJN Book of the Year; 2005.

4. Cutcliffe J.R., McKenna H.P., Hyrkas K., Barker P.J. Modelos de enfermería: Aplicación a la práctica. México: El Manual Moderno; 2001.

5. Hernández Sampieri R, Fernández Collado C, Baptista Lucio P. Metodología de la Investigación $4^{\mathrm{a}}$ ed. México: Mc Graw Hill; 2006.

6. Arnold T., Stanley J., Fellowes E., Moncada G.R.A., Hutchinson J., Kerstein M.D. Estudio prospectivo, multicéntrico de gestionar las úlceras venosas de las extremidades inferiores. Ann Vasc Surg. 1994; 8(4), 356-362.

7. Jaramillo O. El programa de las heridas. Dundee: Centre for Medical Education The University of Dundee. 1994.

8. OMS. Reto mundial el pro de la seguridad del paciente 2005-2006. Ginebra, Suiza: World Health Organization. 2005.

9. Asmussen P., Sollner B. El cuidado de las heridas. Principios para la curación de las heridas. Alemania: Beiersdorf medical Bibliothek. 1995.

10. OMS. (s.f.). Una atención limpia es una atención más segura. Retrieved septiembre 8, 2011, from Organización Mundial de la Salud: http://www.who.int/gpsc/es/

11. Martínez C., Betín K., Caldera K., Guerra J., Hernández M., Villalba M. Adherencia del personal de enfermería a las medidas de prevención y control de infecciones intrahospitalarias en tres Unidades de Cuidados Intensivos. Investigaciones Andinas. 2012; 14(24), 372-384.

12. Flores I. Manejo avanzado de herida. Revista Mexicana de Enfermería Cardiológica. 2006; 14(1), 24-28.

13. Sibbald R.G., Williamson D., Orsted H.L., Campbell K., Keast D., Krasner D., et al. Preparing the wound bed--debridement, bacterial balance, and moisture balance. Ostomy Wound Manage. 2000; 46(11), 14-22.

14. Boxer A.M., Gottesman N., Bernstein H., Mandl I. Debridement of dermal ulcers and decubiti with collagenase. Geriatrics. 1969; 24(7), 75-86.

15. Reilly J., Allardice G., Bruce J., Hill R., McCoubrey J. Procedure-specific surgical site infection rates and postdischarge surveillance in Scotland. Infect Control Hosp Epidemiol. 2006; 1318-1323.

16. Daneman N., Thiruchelvam D., Redelmeier D.A. Statin use and the risk of surgical site infections in elderly patients undergoing elective surgery. Arch Surg. 2009; 144(10), 938-945.

17. Harbarth S., Samore M. H., Lichtenberg D., Carmeli Y. Prolonged antibiotic prophylaxis after cardiovascular surgery and its effect on surgical site infections and antimicrobial resistance. Circulation. 2009; 2916-2921. 
18. Keen D., James J. A tool to aid nurses' decision making in relation to dressing selection. Br J Nurs. 2004; 13(15), S6-14.

19. Graham I. D., Harrison M. B., Shafey M., Keast D. Knowledge and attitudes regarding care of leg ulcers. Survey of family physicians. Can Fam Physician. 2003; (49), 896-902.

20. Sibbald R. G., Browne A. C., Coutts P., Queen D. Screening evaluation of an ionized nanocrystalline silver dressing in chronic wound care. Ostomy Wound Management. 2001; 47(10), 38-43.

21. Mengarelli R.H., Bilevich E., Belatti A., Cevallos M.V., Gorosito S. Antisépticos y heridas crónicas. Act Terap Dermatol. 2013; (39), 234-239.

22. Sánchez Saldaña L., Sáenz Anduaga E. Antisépticos y desinfectantes. Dermatología Peruana. 2005; 15(2), 82-103.

23. Ángeles Garay U., Velázquez Chávez Y., Molinar Ramos F., Anaya Flores V. E., Uribe Márquez S.E. Estimación de la estancia adicional en pacientes con infección hospitalaria. Rev Med Inst Mex Seguro Soc. 2009; 47(4), 387-392.

24. Herwaldt L.A., Cullen J. J., Scholz D., French P., Zimmerman M.B., Pfaller M.A., Perl T. M.A prospective study of outcomes, healthcare resource utilization, and costs associated with postoperative nosocomial infections. Infect Control Hosp Epidemiol. 2006; 27(12), 12911298.

25. Edwards R., Harding K.G. Bacteria and wound healing. Current Opinion in Infectious Diseases. 2006; 17(2), 91-96.

26. Sibbald R.G., Orsted H., Schultz G.S., Coutts P., Keast D. Preparing the wound bed 2003: Focus on infection and inflammation. OstomyWound Management. 2003; 24(11), 24-51.

27. Schultz G.S., Sibbald R.G., Falanga V., Ayello E.A., Dowsett C., Harding K., Vanscheidt W. Wound bed preparation: a systematic approach to wound management. Wound Repair Regen. 2003; (11), Suppl 1:S1-28.

28. Alligood M. R., Marriner Tomey A. Modelos y teorías en enfermería. España: Elsevier; 2007.

29. Quintero M. (2000). Espiritualidad y afecto en el cuidado de enfermería. In M. Quinter, Cuidado y práctica de enfermería (pp. 184-191). Bogotá: Universidad Nacional de Colombia. 